\title{
PENGARUH KOMPETENSI TERHADAP KINERJA DOSEN SEKOLAH TINGGI ILMU EKONOMI RIAU
}

\author{
Sudarmin Manik ${ }^{1}$; Nova Syafrina ${ }^{2}$ \\ ${ }^{1,2}$ Sekolah Tinggi Ilmu Ekonomi Riau \\ Jln. HR Subrantas KM 12 Panam Pekanbaru \\ E-mail : amin.manik@yahoo.com
}

\begin{abstract}
The purpose of this study is to determine the effect of competence on the performance of lecturers at the STIE of Riau. The population in this research is the lecturer of STIE Riau which amounted to 54 people. And the sample amounted to 54 people by using sampling technique that is sampling saturated. Data analysis was performed by using reliability test, simple linear regression, $\mathrm{R} 2$ test and t test. The test is conducted in order to determine the effect of competence on the performance of lecturers of the STIE of Riau. Based on the result of research that competence with $\mathrm{R}$ square value can be 0,541 , which means competence contributed $54,1 \%$ to lecturer performance, and have positive and significant influence to lecturer performance with sig level. 0,000 . The conclusion from the research that the hypothesis of competence acceptable truth
\end{abstract}

Keywords: competence, lecturer performance

\section{PENDAHULUAN}

Dewasa ini kemajuan bangsa tergantung kepada sumber daya manusia yang ada. Semakin maju suatu negara memerlukan sumber daya manusia yang berkualitas. Dalam era globalisasi sekarang ini, masyarakat Indonesia dituntut agar memiliki kualitas intelektual yang mampu bersaing dengan bangsa asing.

Dalam hal ini negara bergantung dengan mahasiswa sebagai calon generasi penerus bangsa. Untuk meningkatkan kualitas mahasiswa agar mampu bersaing dengan internasional, mahasiswa harus bekerja keras dalam belajar. Keberhasilan mahasiswa dalam belajar bergantung dengan dosen yang berkualitas.

Dosen yang berkualitas adalah dosen yang memiliki kompetensi dalam melaksanakan proses belajar mengajar. Adapun kompetensi yang harus dimiliki seorang dosen dalam melaksanakan tugasnya adalah kompetensi pedagogik, kompetensi kepribadian, kompetensi profesional dan kompetensi sosial. Hal ini sudah tertuang dalam Undang-
Undang guru dan dosen nomor 14 tahun 2005 pasal 8 yaitu Guru dan dosen wajib memiliki kualifikasi akademik, kompetensi, sertifikat pendidik, sehat jasmani dan rohani, serta memiliki kemampuan untuk mewujudkan tujuan pendidikan nasional. Berikutnya pada pasal 10 ayat 1 bahwa Kompetensi guru sebagaimana dimaksud dalam Pasal 8 meliputi kompetensi pedagogik, kompetensi kepribadian, kompetensi sosial, dan kompetensi profesional yang diperoleh melalui pendidikan profesi. Keempat kompetensi tersebut terintegrasi dalam kinerja dosen.

Sekolah Tinggi Ilmu Ekonomi Riau (STIE-R) adalah salah satu Perguruan Tinggi swasta di Kota Pekanbaru yang memiliki jurusan Manajemen dan akuntansi. Dengan peringkat akreditasi manajemen $\mathrm{B}$ dan akuntansi C.

STIE Riau juga merupakan salah satu Sekolah Tinggi yang diminati masyarakat sekitar pada saat ini. Baik di kota pekanbaru maupun diluar kota Pekanbaru. Dengan banyaknya mahasiswa setiap tahun nya, STIE Riau harus 


\section{Jurnal Ilmiah Ekonomi dan Bisnis}

Vol. 15. No.1, Maret 2018: 1-6

EISSN : $2442-9813$

ISSN : $1829-9822$

memiliki jumlah dosen yang sesuai dengan jumlah mahasiswa. Sehingga rasio dosen dengan jumlah mahasiswa dapat terpenuhi. Berikut adalah jumlah dosen STIE Riau dalam kurun waktu lima tahun terakhir.

Jumlah dosen pada Sekolah Tinggi Ilmu Ekonomi Riau masih belum memenuhi rasio. Dengan jumlah mahasiswa S1 Manajemen tahun 2016/2017 sebanyak 2.518. dengan jumlah dosen 48 berarti rasio antara dosen dengan mahasiswa 1:53. Dan D3 Akuntansi dengan jumlah mahasiswa 236 dengan perbandingan rasio 1:39,3. Dengan ketentuan dikti rasio dosen 1:35, hal ini berarti pada Sekolah Tinggi Ilmu Ekonomi Riau masih membutuhkan dosen untuk memenuhi rasio.

Dosen Sekolah Tinggi Ilmu Ekonomi Riau yang telah memiliki Sertifikat AA (Pekerti) pada tahun ajaran 2017/2018 sudah seluruhnya mengikuti pelatihan AA (Pekerti) hal ini dapat meningkatkan kinerja dosen yang sangat baik. Sedangkan untuk dosen yang sertifikasi pada tahun ajaran 2017/2018 meningkat dari tahun ajaran sebelumnya. Dari 2 orang meningkat menjadi 18 orang. Dengan meningkatnya dosen yang disertifikasi maka akan meningkatkan kinerja profesional dosen pada Sekolah Tinggi Ilmu Ekonomi Riau.

Masih ada beberapa dosen yang belum meiliki jabatan fungsional, yaitu masih tenaga pengajar. Hal ini akan membuat kinerja dosen kurang maksimal.

\section{TINJAUAN PUSTAKA}

Dessler dalam Sutrisno (2016) manajemen sumber daya manusia dapat didefinisikan suatu kebijakan dan praktik yang diperlukan seseorang yang menjalankan aspek orang atau sumber daya manusia dari posisi seseorang manajemen, mulai dari perekrutan sampai dengan penilaian
Manajemen Sumber Daya Manusia adalah ilmu dan seni mengatur hubungan dan peranan anggota organisasi agar efektif dan efisien agar terwujudnya tujuan perusahaan, karyawan, dan masyarakat (Melayu Hasibuan, 2016)

Sinambela (2016) Manajemen SDM dapat didefinisikan sebagai suatu pengelolaan dan pendayagunaan sumber daya yang ada pada individu. Sihotang dalam Sinambela (2016:8) MSDM adalah keseluruhan proses perencanaan, pengorganisasian, pengarahan dan pengawasan terhadap kegiatan pengadaan seleksi, pelatihan, penempatan, pemberian kompensasi, pengembangan, pengitegrasian, pemeliharaan, dan pelepasan SDM untuk tercapainya berbagai tujuan individu, masyarakat, pelanggan pemerintah dan organisasi yang bersangkutan.

Menurut Fahmi (2014) kinerja adalah hasil yang diperoleh oleh suatu anggota organisasi baik organisasi tersebut bersifat profit oriented dan non profit oriented yang dihasilkan selama kurun waktu tertentu.

Wibowo (2007) kinerja merupakan hasil kerja yang mempunyai hubungan kuat dengan tujuan organisasi, memberikan kontribusi pada ekonomi. Dengan demikian, kinerja adalah tentang bagaimana melakukan pekerjaan dan bagaimana cara mengerjakannya. Kinerja adalah hasil kerja yang telah dicapai pegawai dari tingkah laku kerjanya dalam melaksanakan kerja (Edy Sutrisno, 2015).

Simanjuntak dalam Rivai (2009:406) kinerja adalah tingkat pencapaian hasil atas pelasksanaan tugas tertentu. Bastian dalam Fahmi (2014:128) kinerja adalah gambaran mengenai tingkat pencapaian pelaksanaan suatu kegiatan/program/kebijaksanaan dalam mewujudkan sasaran tujuan, misi dan visi organisasi yang tertuang dalam perumusan skema strategik suatu organisasi. 
Amstrong dalam penemuan Marliana Budhiningtias Winanti (Majalah Ilmiah UNIKOM, 2011:256) mengemukakan tentang bagaimana mengelola kinerja dan bagaimana menempatkannya dalam praktek. Terdapat empat faktor pokok dalam kinerja, yaitu input, process, output, dan outcome. Input: Keterampilan, pengetahuan, dan keahlian dalam membawa pekerjaan mereka. Hal ini menyangkut artibusi individual. Process : Bagaimana individu memiliki kepercayaan dalam melaksanakan pekerjaan mereka. Hal ini menyangkut perilaku kemampuan yang dibawa dalam pekerjaan untuk mengisi tanggung jawab. Output : Hasil terukur yang dicapai oleh individu sesuai dengan tingkat kinerja yang dicapai dalam melaksanakan tugas-tugas mereka. Hal ini merupakan ukuran kinerja yang di capai seseorang. Outcomes : Dampak apa yang telah dicapai oleh kinerja individu dari hasil tim mereka, departemen, unit dan organisasi.

Menurut Bernardin dan Russel oleh Noor Arifin (Jurnal Economia, 2012:13-14), ada lima kinerja karyawan secara individu, yaitu: Kualitas, artinya hasil kegiatan yang dilakukan mendekati sempurna, dalam arti menyesuaikan beberapa cara ideal dari penampilan kegiatan dalam memenuhi tujuan yang diharapkan dari suatu kegiatan. Kuantitas, yaitu jumlah atau target yang dihasilkan dan dinyatakan dalam istilah unit jumlah siklus aktivitas yang diselesaikan. Pengetahuan dan keterampilan, yaitu pengetahuan dan keterampilan yang dimiliki oleh karyawan. Ketepatan waktu, yaitu aktivitas yang diselesaikan pada waktu awal yang diinginkan dilihat dari sudut koordinasi dari hasil output serta memaksimalkan waktu yang tersedia untuk aktivitas lain. Komunikasi, yaitu hubungan atau interaksi dengan sesama rekan kerja dalam organisasi.
Dari faktor-faktor tersebut dapat diperoleh indikator-indikator dari variabel kinerja kerja dalam penelitian Marliana Budhiningtias Winanti (2011:256), sebagai berikut : Indikator dari sub variabel input : Keterampilan yang dimiliki dosen; Pengetahuan yang dimiliki dosen; Keahlian yang dimiliki dosen. Indikator dari sub variabel process : Kepercayaan dosen dalam melaksanakan pekerjaan. Indikator dari sub variabel output : Hasil kinerja dosen, Indikator sub variabel outcomes : Dampak kinerja dosen terhadap mahasiswa dan fakultas

Boyatzis dalam Hutapea dan Nurianna Thoha (2008) kompetensi adalah kapasitas yang ada pada seseorang yang bisa membuat orang tersebut mampu memenuhi apa yang disyaratkan oleh pekerjaan dalam suatu organisasi sehingga organisasi tersebut mampu mencapai hasil yang diharapkan.

Menurut Trotter dalam Saifuddin (2004) mendefinisikan bahwa seorang yang berkompeten adalah orang yang dengan keterampilannya mengerjakan pekerjaan dengan mudah, cepat, intuitif dan sangat jarang atau tidak pernah membuat kesalahan.

Sedangkan menurut Finch \& Crunkilton, (1992: 220) Menyatakan "Kompetencies are those taks, skills, attitudes, values, and appreciation thet are deemed critical to successful employment". Pernyataan ini mengandung makna bahwa kompetensi meliputi tugas, keterampilan, sikap, nilai, apresiasi diberikan dalam rangka keberhasilan hidup/penghasilan hidup. Hal tersebut dapat diartikan bahwa kompetensi merupakan perpaduan antara pengetahuan, kemampuan, dan penerapan dalam melaksanakan tugas di lapangan kerja.

Kompetensi guru dan Dosen terkait dengan kewenangan melaksanakan tugasnya, dalam hal ini dalam menggunakan bidang studi sebagai bahan pembelajaran yang berperan sebagai alat 


\section{Jurnal Ilmiah Ekonomi dan Bisnis}

Vol. 15. No.1, Maret 2018: 1-6

EISSN : $2442-9813$

ISSN : 1829-9822

pendidikan, dan kompetensi pedagogis yang berkaitan dengan fungsi guru dan Dosen dalam memperhatikan perilaku peserta didik belajar (Mahasiswa) (Djohar, 2006 : 130).

Dalam Undang-Undang guru dan dosen nomor 14 tahun 2005 pasal 8 yaitu Guru dan dosen wajib memiliki kualifikasi akademik, kompetensi, sertifikat pendidik, sehat jasmani dan rohani, serta memiliki kemampuan untuk mewujudkan tujuan pendidikan nasional. Berikutnya pada pasal 10 ayat 1 bahwa Kompetensi guru sebagaimana dimaksud dalam Pasal 8 meliputi kompetensi pedagogik, kompetensi kepribadian, kompetensi sosial, dan kompetensi profesional yang diperoleh melalui pendidikan profesi. Keempat kompetensi tersebut terintegrasi dalam kinerja dosen.

Jadi indikator dalam penelitian ini adalah: Kompetensi Pedagigik, Kompetensi Pribadi, Kompetensi Sosial, Kompetensi Profesional

\section{METODE PENELITIAN}

Penelitian ini dilakukan di Sekolah Tinggi Ilmu Ekonomi Riau Jalan HR. Subrantas No. 57 Panam Pekanbaru. Dalam penulisan skripsi ini, penulis menggunakan cara pengumpulan data melalui kuisioner berupa daftar pertanyaan yang disebarkan kepada seluruh Dosen Tetap Sekolah Tinggi Ilmu Ekonomi Riau. Untuk mengetahui pengaruh kompetensi terhadap kinerja dosen, digunakan skala likert. Skala likert digunakan untuk mengukur sikap, pendapat dan presepsi seseorang atau kelompok orang tentang fenomenal sosial. Dengan skala likert, maka variabel yang diukur dan dijabarkan menjadi indikator variabel.

Populasi dalam penelitian ini dilakukan kepada seluruh dosen Sekolah Tinggi Ilmu Ekonomi Riau yang berjumlah 54 orang. Dalam penelitian ini penulis menggunakan teknik
Sampling Jenuh. Jadi sampel dalam penelitian ini adalah 54 orang dosen. Teknik analisis data yang digunakan adalah teknik kuantitatif dengan persamaan regresi linier sederhana.

\section{HASIL DAN PEMBAHASAN}

Setelah data kuesioner terkumpul, maka dilakukan pengolahan data dengan bantuan SPSS 23. Dan didapat outputnya sebagai berikut:

Model Summary ${ }^{b}$

\begin{tabular}{|l|l|l|l|l|l|}
\hline Model & $\mathrm{R}$ & $\begin{array}{l}\mathrm{R} \\
\text { Square }\end{array}$ & $\begin{array}{l}\text { Adjusted } \\
\text { R Square }\end{array}$ & $\begin{array}{l}\text { Std. Error } \\
\text { of the } \\
\text { Estimate }\end{array}$ & $\begin{array}{l}\text { Durbin- } \\
\text { Watson }\end{array}$ \\
\hline 1 & $.736^{\mathrm{a}}$ & .541 & .514 & 3.453 & 2.381 \\
\hline
\end{tabular}

a. Predictors: (Constant), KOMPETENSI

b. Dependent Variable:

KINERJA DOSEN

Dari hasil output SPSS diatas nilai $\mathrm{R}=0,736$, hal ini berarti secara simultan insentif dan kepuasan kerja memiliki hubungan yang sangat erat terhadap kinerja karyawan. Sedangkan nilai R square 0,541 , hal ini berarti kompetensi memberikan sumbangan pengaruh terhadap kinerja sebesar 54,1\%. Sisanya dipengaruhi variabel lain yang tidak dikaji dalam penelitian ini.

Coefficients $^{\mathrm{a}}$

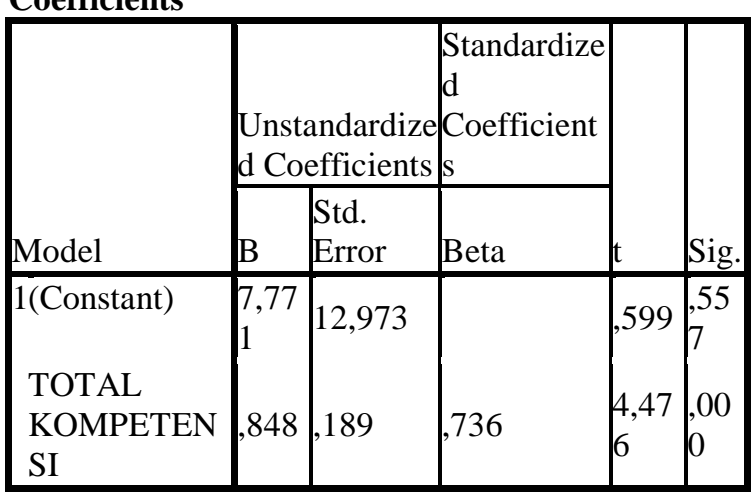

Dari hasil output SPSS diatas didapat persamaan regresi sebagai berikut: $\mathrm{Y}=7,771+0,848 \mathrm{X}$

Dari hasil tersebut dapat disimpulkan bahwa

a. Konstanta sebesar 7,771. Hal ini berarti jika kompetensi bernilai nol, 
Jurnal Ilmiah Ekonomí dan Bisnis

Vol. 15. No. 1, Maret 2018: 1-6

EISSN : $2442-9813$

ISSN : $1829-9822$

maka kinerja dosen masih bernilai 7,771 satuan.

b. Koefesien regresi kompetensi 0,848 . Hal ini berarti, jika variabel kompetensi dinaikkan 1 satuan. Maka kinerja dosen akan mengalami kenaikan sebesar 0,848 satuan

Uji t

Dari hasil regresi diatas dapat disimpulkan sebagai berikut: $\mathrm{T}$ hitung variabel kompetensi lebih besar dari $\mathrm{t}$ tabel, dan tingkat signifikasi 0,000 lebih kecil dari 0,05 . Hal ini berarti kompetensi berpengaruh signifikan terhadap kinerja dosen Sekolah Tinggi Ilmu Ekonomi Riau.

Berdasarkan hasil penelitian tersebut maka dapat dibuktikan bahwa kompetensi seorang dosen berpengaruh positif dan signifikan terhadap kinerja dosen dalam bekerja.

Hasil penelitian ini menunjukkan bahwa dibutuhkan kompetensi bagi seorang dosen dalam mengajar, meneliti dan melakukan pengabdian. Kompetensi yang dimiliki ini akan sangat menunjang kondisi dimana dosen akan berhasil dalam menjalankan tugas tridharmanya.

\section{KESIMPULAN DAN SARAN}

Dari hasil penelitian ini dapat disimpulkan beberapa hal sebagai berikut: Dari hasil output SPSS diatas nilai $\mathrm{R}=0,736$, hal ini berarti secara simultan insentif dan kepuasan kerja memiliki hubungan yang sangat erat terhadap kinerja karyawan. Sedangkan nilai $\mathrm{R}$ square 0,541, hal ini berarti kompetensi memberikan sumbangan pengaruh terhadap kinerja sebesar 54,1\%. Sedangkan dari hasil Uji $t$ atau uji hipotesis bahwa kompetensi berpengaruh signifikan terhadap kinerja dosen Sekolah Tinggi Ilmu Ekonomi Riau.

Diharapkan kepada dosen Sekolah Tinggi Ilmu Ekonomi Riau dapat meningkatkan kinerjanya melalui keahlian masing-masing dengan cara meningkatkan jabatan fungsional dan sertifikasi dosen.

\section{DAFTAR PUSTAKA}

Arikunto, Suharsimi, 2010. Prosedur Penelitian, Edisi Revisi, Rineka Cipta, Jakarta.

Djohar. (2006). Guru, Pendidikan dan Pembinaannya (Penerapannya dalam Pendidikan dan UndangUndang Guru dan Dosen). Yogyakarta : Sinar Grafika

Fahmi, Irham. 2014. Perilaku Organisasi. Alfabeta. Bandung

Finch, \& Crunkilton. (1992). Curriculum development in vocational and technical education. Planning, content and implementation. Fourth edition. Virginia: Polytechnic Institute and State University

Hasibuan, Melayu. 2016. Maanajemen Sumber Daya Manusia. Cetakan kesembilan. Bumi Aksara. Jakarta.

Hutapea, Thoha. 2008. Kompetensi Plus. Jakarta: PT Gramedia Pustaka Utama

Priyatno, Duwi, 2008. Mandiri Belajar SPSS (Statistical Product and Service Solution), MediaKom, Yogyakarta.

Rivai, Veithzal. 2009. Manajemen Sumber Daya Manusia untuk Perusahan. PT. RajaGrafindo Persada. Jakarta

Saifudin. 2004.'Pengaruh Kompetensi dan Independensi Terhadap Opini Audit Going Concern (Studi Kuasieksperimen Pada Auditor Dan Mahasiswa)". Tesis Program 
Jurnal Ilmiah Ekonomi dan Bisnis

Vol. 15. No.1, Maret 2018: 1-6

EISSN : $2442-9813$

ISSN : $1829-9822$

Pasca Sarjana Magister

Akuntansi

Universitas

Diponegoro

Sinambela, Lijan Poltak. 2016 Manajemen Sumber Daya Manusia.Bumi Aksara. Jakarta

Sugiyono, 2010. Metode Penelitian Administrasi, Cetakan XVIII, Alfabeta, Bandung. 2012. Metode Penelitian Bisnis. Alfabeta. Bandung

Sutrisno, Edy. 2016. Manajemen Sumber Daya Manusia. Prenadamedia Group. Jakarta
2015. Manajemen Sumber Daya Manusia,Kencana Prenada Media Group, Jakarta.

Undang-Undang guru dan dosen nomor 14 tahun 2005

Wibowo, 2007. Sistem Mananjemen Kinerja, PT. Raja Grafindo Persada, Jakarta.

Winanti. Majalah UNIKOM. 2011. Jurnal Majalah Ilmiah Unikom Universitas Komputer Indonesia. 